\title{
Effect of direct-current countershock on atrial flutter with complete heart block in a case of staphylococcal septicaemia
}

\author{
JAMES BUCHANAN* \\ M.D., M.R.C.P. (Edin.)., M.R.C.P. (Glasg.) \\ Senior Registrar \\ RONALD J. WeIR \\ M.B., M.R.C.P. (Glasg.) \\ Registrar \\ Department of Medicine, Victoria Infirmary, Glasgow
}

IN THE COURSE of staphylococcal septicaemia myocardial damage of varying severity may occur and cardiac arrhythmia may develop (Sanson, Slodki \& Gruhn, 1963).

This report describes a patient who had severe staphylococcal infection and whose electrocardiograms showed an unusual series of arrhythmias. A further point of interest lies in the restarting of ventricular systole on more than thirty occasions by praecordial blows, during preparation for the insertion of an artificial pacemaker.

\section{Case report}

This man aged 55 years developed an influenza-like illness in mid-July 1966 . He was given tetracycline with seeming improvement. On 26 July, however, his temperature increased to $103^{\circ} \mathrm{F}$ and his general condition deteriorated sharply.

On admission to the Victoria Infirmary, Glasgow, he was drowsy, confused and appeared very ill. He had labial herpes and finger clubbing. There was evidence of dehydration. BP $90 / 40 \mathrm{mmHg}$. Scanty moist sounds were heard at the left lung base but there were no other signs of cardiac failure. Clinically the heart was slightly enlarged with a loud harsh praecordial systolic murmur. Atrial flutter with an irregular, rapid ventricular response was seen in the electocardiogram (Fig. 1a).

A portable X-ray film of chest showed prominence of the left ventricular segment of the heart shadow and unfolding of aorta but the lung fields appeared clear. $\mathrm{Hb} 14.2 \mathrm{~g} / 100 \mathrm{ml}$, WBC $17,500 / \mathrm{mm}^{3}, \quad 88 \%$ neutrophils. There was moderate albuminuria but no pyuria and urine culture yielded no organisms. CSF normal. Blood culture yielded Staphylococcus aureus

*Present appointment: Consultant Physician, Law Hospital, Carluke, Lanarkshire. pyogenes (coagulase positive). Antibiotic therapy was changed to penicillin 8 mega-units daily and streptomycin.

Because of the persistence of a rapid ventricular rate, digoxin was started on the morning of 27 July but only three doses of $0.25 \mathrm{mg}$ were given as his heart rate had decreased to about $80 /$ min by 16.30 hours (Fig. 1b). At 17.00 hours atrial flutter continued but there was ventricular asystole (Fig. 1c) associated with a Stokes-Adams

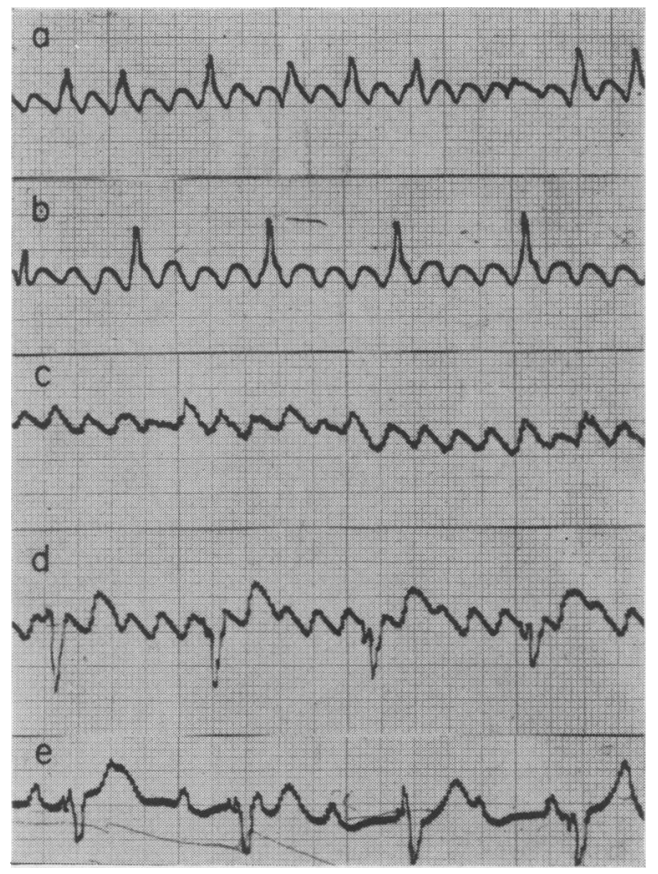

Fig. 1. ECG (lead 2) showing: (a) atrial flutter with rapid ventricular response, (b) atrial flutter with slower ventricular response, (c) atrial flutter with ventricular asystole, (d) atrial flutter with complete heart block, and (e) sinus beats with complete heart block. 
attack. After a short period of external cardiac compression, spontaneous regular ventricular systole ensued at approximately 60 beats $/ \mathrm{min}$, while atrial flutter persisted (Fig. 1d). The QRS complexes did not resemble those observed initially and it was realized that complete atrioventricular dissociation had developed.

Direct-current shock (50 w-secs) converted the atrial rhythm to sinus type. The cardiogram showed ventricular beats similar in form and rate to those seen just before cardioversion and complete heart block was clearly present (Fig. 1e).

Repeated episodes of ventricular asystole with Stokes-Adams attacks followed. While arrangements were being made for pacing, ventricular rhythm was started on more than thirty occasions by a praecordial blow. Fig. 2 shows the effect of these blows on the ECG on two occasions, each shown by an asterisk.

That evening a transvenous pacemaker was inserted and its tip impacted in the right ventricular wall. Satisfactory ventricular pacing was obtained and good peripheral arterial pulsation was felt.

Next morning (28 July) cardiac rhythm was sinus in type with first degree atrioventricular block (PR interval $0.26 \mathrm{sec}$ ) and right bundlebranch block. The patient's general condition was essentially unchanged. He had continuing mental confusion and pyrexia $\left(100 \cdot 2^{\circ} \mathrm{F}\right)$.

By the morning of 29 July heart block had disappeared, the PR interval being $0.20 \mathrm{sec}$. There was now a loud blowing diastolic murmur at the left sternal border and blood pressure was $160 / 60 \mathrm{mmHg}$, strongly suggesting aortic valve

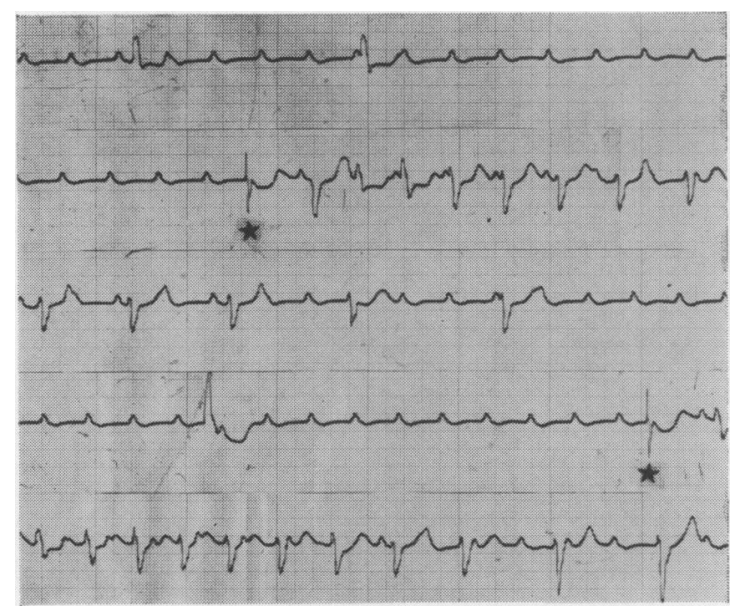

FIG. 2. ECG (lead 2) showing complete heart block with gradual slowing of ventricular beats to asystole and restoration of ventricular beats by praecordial blows on two occasions (asterisked). regurgitation. Peripheral circulatory failure ensued on 30 July. Digoxin and intravenous hydrocortisone were given without improvement. Later that day he developed ventricular fibrillation and died. Necropsy was refused.

\section{Comment}

Gore \& Saphir (1947) found myocardial involvement in thirty-four of 107 cases of staphylococcal septicaemia. Sanson et al. (1963) commented on the occurrence of myocardial abscesses, often minute, in cases of severe staphylococcal infection. Arrhythmias did not dominate the clinical picture but included atrial fibrillation, first degree atrioventricular block and right bundle-branch block, akin to the abnormal rhythms observed in our case. Matthew (1951) also reported first degree atrio-ventricular block in a case of staphylococcal endocarditis with focal embolic infarction of the myocardium.

Atrial flutter with complete heart block is an uncommon arrhythmia. In the present case, the alteration in the form of the QRS complexes and the onset of a slower regular ventricular rhythm are in themselves features suggesting complete heart block. Further, when atrial flutter was terminated by cardioversion and sino-atrial beats become evident in the ECG (Fig. 1e), the ventricular complexes were unchanged in contour and rate. The part played by digoxin in producing the heart block is uncertain.

Restoration of the heart beat by a praecordial blow was first described by Schott (1920) in a case of Stokes-Adams attack due to asystole. Subsequent reports have in general confirmed the effectiveness of this manoeuvre. Semple et al. (1963) reported three patients thus resuscitated. Roberts, Schnabel \& Ravdin (1954) described a patient in whom two attacks of asystole were ended in this manner. Restoration of ventricular beats on as many as thirty occasions within an hour does not seem to have been reported previously. On most occasions ectopic beats followed immediately on the blow, as shown in Fig. 2. Ventricular ectopic impulses of this type have been reported by Scherf \& Bornemann (1960).

\section{Acknowledgments}

We are grateful to Dr T. Semple for his stimulating and helpful advice in the preparation of this paper.

\section{References}

Gore, I. \& SAPHIR, O. (1947) Myocarditis. A classification of 1,402 cases. Amer. Heart J. 34, 827.

MatTHEw, H. (1951) Subacute bacterial endocarditis caused by coagulase-negative staphylococcus albus. Lancet, $\mathbf{i}, 146$. 
Roberts, B., Schnabel, T.G. \& Ravdin, I.S. (1954) Multiple episodes of cardiac arrest. Report of a case. J. Amer. med. Ass. 154, 581.

Sanson, J., Slodki, S. \& Gruhn, J.G. (1963) Myocardial abscesses. Amer. Heart J. 66, 301.

SCHERF, D. \& BornemanN, C. (1960) Thumping of the precordium in ventricular standstill. Amer. J. Cardiol. 5, 30.
Schотт, E. (1920) Ueber Ventrikellstillstand (AdamsStokes'sche Anfalle) nebst Bemerkungen ueber andersartige Arhythmien passagerer Natur. Dtsch. Arch. klin. Med. 131, 211.

Semple, T., Dall, J.L.C., Lancaster, W.M., Wang, I., Grigor, K. \& PeEL, A.A.F. (1963) The management of medical cardiac arrest. Scot. med.J. 8, 475.

\title{
Congenital shortening of one femur in one identical twin
}

\author{
C. E. A. HoldeN* \\ M.B., B.S., F.R.C.S. \\ Orthopaedic Registrar, Lambeth Hospital, London, S.E.11
}

Congenital shortening of the femur has been described by Ring (1961) as one of a group of congenital abnormalities of the femur. In a series of nineteen such cases, Ring (1959) includes twins where the presence of congenital shortening of one femur in one twin led to the examination and discovery of the same defect in the other twin. The purpose of this paper is to record the presence of congenital shortening of one femur in only one of identical twins and to assess the significance of this as regards the aetiology of this condition.

\section{Case report}

Mrs D.C., a 27-year-old West Indian, having previously been delivered of three normal male children, was spontaneously delivered of female twins. The pregnancy lasted 42 weeks and had been entirely normal. There was no pyrexial illness in the first trimester. The mother had taken no drugs, she had had no glycosuria, her Wasserman Reaction was negative and her blood group was $O$, rhesus positive.

The single placenta had two amniotic sacs and one chorion. The older child weighed $5 \mathrm{lb} 15 \mathrm{oz}$ with a body length of 20 in. and a head circumferance of $13 \frac{1}{2}$ in. The younger child weighed $6 \mathrm{lb} 15 \mathrm{oz}$ with a body length of $20 \mathrm{in}$. and a head circumference of 14 in.

After delivery, it was noticed that the elder twin appeared to have shortening of the left leg above the knee. The left hip abduced to only $90^{\circ}$. There were no other abnormalities detected clinically. X-ray at that time (Fig. 1) showed shortening of the shaft of the left femur with lateral bowing. The cortex of the diaphysis was thickened, almost obliterating the medullary

*Present address: Bristol Royal Infirmary, Bristol, 2. cavity. The centre of ossification for the lower femoral epiphysis was present on both sides, but the centre for the upper tibial epiphysis was present only on the normal side. The hip joints on both sides appeared normal.

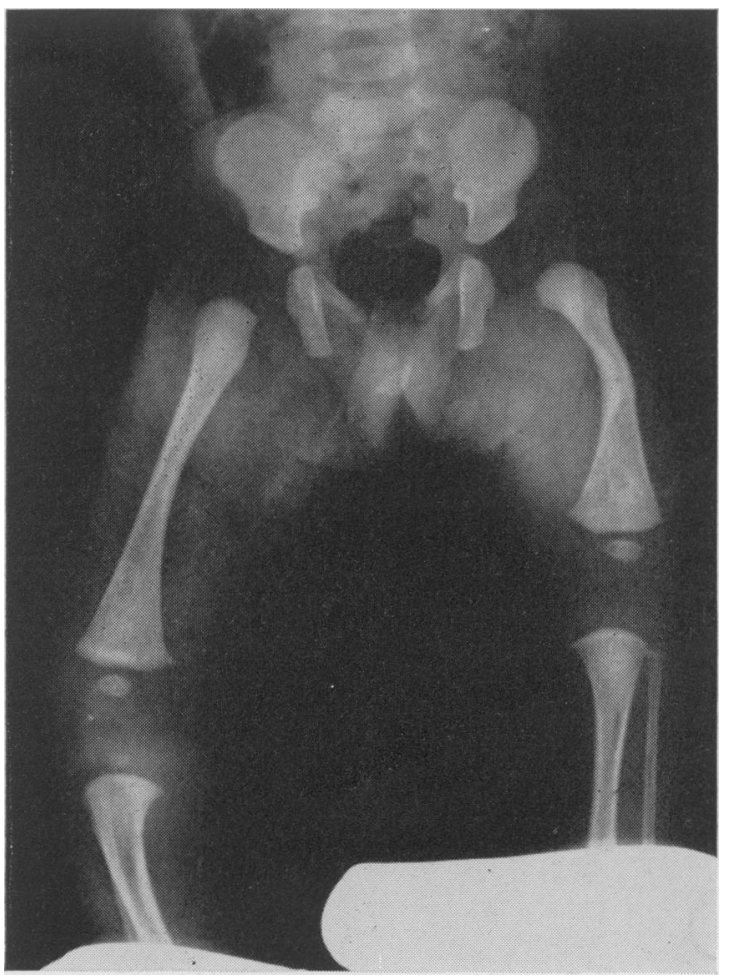

FIG. 1. X-ray of the affected twin at 1 day old showing shortening and lateral bowing of the left femur. The cortex of the affected femur is thickened almost obliterating the medullary cavity. Note the absence of the centre of ossification for the upper tibial epiphysis on the affected side. 